\title{
Three Cases of Nodular Fasciitis in the Parotid Gland
}

\author{
Heejin Kim ${ }^{1}$, Jeongshik Kim ${ }^{2}$, Ji Sun Kong ${ }^{1}$, and Jin Ho Sohn ${ }^{1}$ \\ ${ }^{1}$ Department of Otorhinolaryngology-Head and Neck Surgery, School of Medicine, Kyungpook National University, Daegu; and \\ ${ }^{2}$ Department of Pathology, College of Medicine, Yeungnam University, Daegu, Korea
}

\author{
이하선에 발생한 결절성 근막염 3예 \\ 김희진 ${ }^{1} \cdot$ 김정식 $^{2} \cdot$ 공지선 $^{1} \cdot$ 손진호 $^{1}$ \\ 경북대학교 의학전문대학원 이비인후과학교실, ${ }^{1}$ 영남대학교 의과대학 병리학교실 ${ }^{2}$
}

\author{
Received September 16, 2014 \\ Revised October 28, 2014 \\ Accepted October 28, 2014 \\ Address for correspondence \\ Heejin Kim, MD \\ Department of Otorhinolaryngology- \\ Head and Neck Surgery, \\ School of Medicine, \\ Kyungpook National University, \\ 130 Dongdeok-ro, Jung-gu, \\ Daegu 700-721, Korea \\ Tel +82-53-200-5777 \\ Fax +82-53-423-4524 \\ E-mail heejin5020@hanmail.net
}

Nodular fasciitis (NF) is a benign tumor-like fibroblastic proliferation, and there have only been few reports about NF involving the parotid gland. Here, we report our experience of three cases of NF in the parotid gland, as well as our evaluation of the diagnostic tools for NF in the parotid gland, such as fine-needle aspiration cytology (FNAC), CT, and clinicopathologic investigations. In the three cases observed, all had growing masses in the parotid gland, and the lesions showed heterogeneous or peripheral rim enhancement on the contrast-enhanced CT, which could have been misdiagnosed as parotid malignancy. On FNAC, the cells had an elongated spindle shape and contained variable amounts of stromal matrix, which could have caused misinterpreted as pleomorphic adenoma. We observed dense cellularity and varying amounts of collagenous stroma, and immunohistochemical staining revealed positive reactivity to CD10, CD34, and smooth muscle actin. NF should be considered in the differential diagnosis of benign and malignant parotid tumors.

Korean J Otorhinolaryngol-Head Neck Surg 2015;58(3):220-3

Key Words Biopsy, fine-needle $\cdot$ Fasciitis · Parotid neoplasms · Pathology · Spiral cone-beam computed tomography.

\section{Introduction}

Nodular fasciitis (NF), a benign tumor-like fibroblastic proliferation, is also known as subcutaneous pseudosarcomatous fibromatosis, infiltrative fasciitis and proliferative fasciitis. NF can be found anywhere in the body and is equally common in men and women. Although any age group can be affected, it is most commonly seen in young adults between 20 and 40 years of age. It usually arises in the subcutaneous tissue with the most common location being the upper extremities $(48 \%)$, especially the volar aspect of the forearm, followed by the trunk (20\%), the head and neck (15-20\%), and the lower extremities $(15 \%))^{1,2)} \mathrm{NF}$ typically arises from the subcutaneous or fascial level, but intramuscular locations and involvement of organs such as the parotid can be present. ${ }^{3)}$
There have been several reports of NF involving the parotid gland, and in this situation, the tumor may be confused with other benign or malignant salivary gland lesions. ${ }^{4,5)}$ Fine-needle aspiration cytology (FNAC), which is the main initial diagnostic investigation for lumps in the parotid gland, is done primarily to distinguish benign tumors from malignant ones. However, FNAC has a diagnostic limitation of its accuracy (84-97\%), sensitivity (54-95\%), and specificity $(86-100 \%) .{ }^{6}$ Although the radiological features of NF have been thoroughly described in the literature, discussions about NF in the head and neck have been relatively sparse.

Here, we report our experience with three cases of NF in the parotid gland, and investigate the value of FNAC, computed tomography (CT), and clinicopathologic examination as tools for diagnosing NF in the parotid gland. 

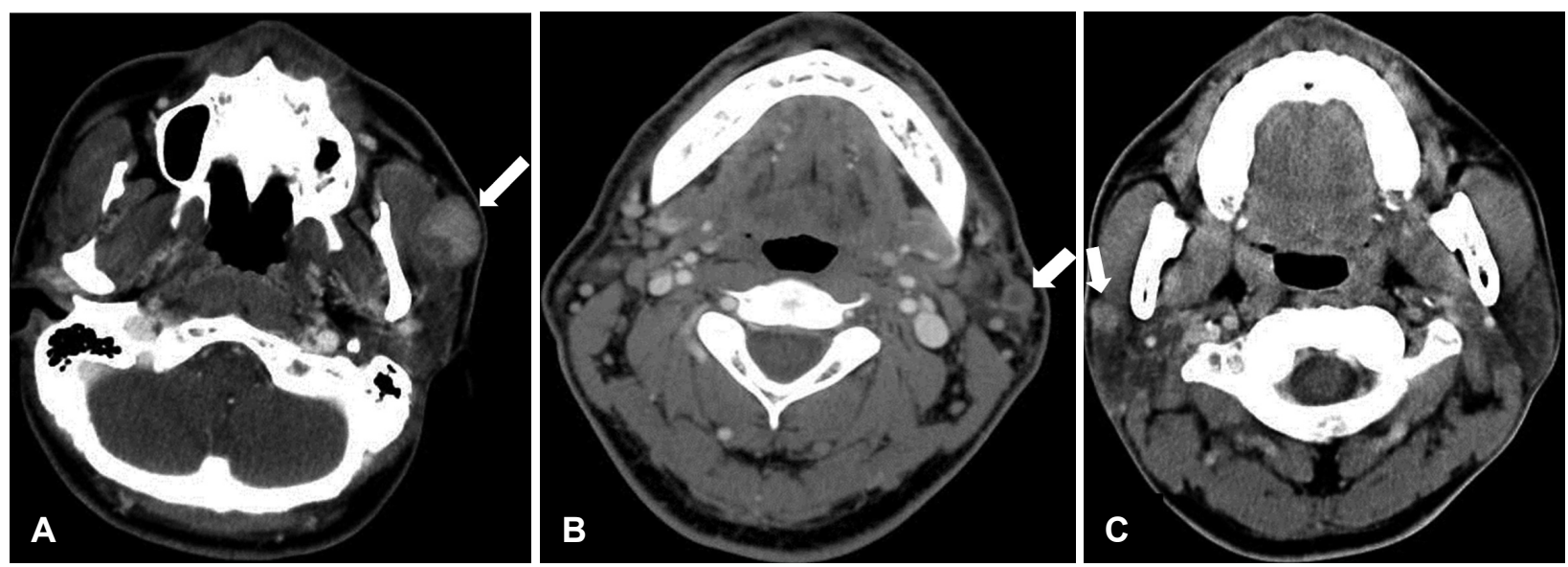

Fig. 1. The computed tomography (CT) findings of nodular fasciitis (NF) in the parotid gland. NF involving the left accessory parotid gland in a 22-year-old man with a palpable cheek mass. Contrast-enhanced CT shows a well-defined, round, moderately enhanced lesion partially embedded in the left masseter muscle (white arrow) (Case 1, A). NF involving the left parotid tail in a 53-year-old man with a palpable neck mass. Contrast-enhanced CT image shows a well-defined round peripheral rim enhanced lesion with adjacent fascial thickening (white arrow) (Case 2, B). NF involving the right parotid tail in a 31-year-old man with a palpable neck mass. Contrast-enhanced CT shows a partly well-defined, ovoid moderately enhanced lesion with adjacent fascial thickening (white arrow) (Case $3, \mathrm{C})$.

Fig. 2. Fine-needle aspiration cytology (FNAC) findings. The smear shows an admixture of hypercellular and hypocellular areas. Small and uniform spindle cells are aggregated and the cells are embedded in loose stroma. The spindle cells have round to oval nuclei. The spindle cells form a short bundle or fascicle. FNAC findings of Case 1 (Papanicolaou stain, $\times 400)(A)$ and FNAC findings of Case 2 (Papanicolaou stain, $\times 400)(B)$.
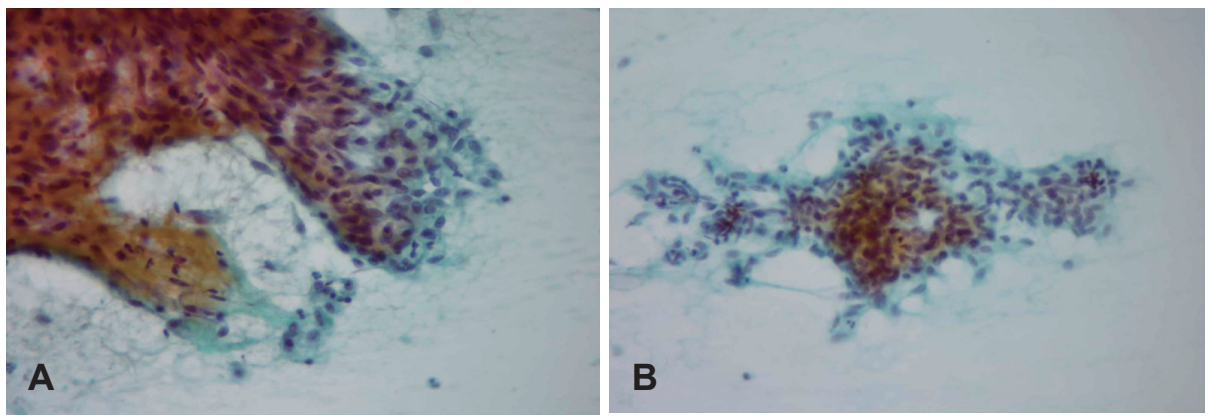

\section{Case}

A 22-year-old man visited our hospital with a $2.5 \mathrm{~cm}$ sized mass in his left cheek that had grown rapidly over the previous 3 months (Case 1). The mass was soft, movable and painless, and there was no history of trauma, or systemic complaints such as fever. The patient underwent a CT scan and FNAC as a diagnostic work-up. The lesion was located in the accessory parotid gland involving a thickening of the parotidomasseteric fascia and the masseter muscle on CT scan. The lesion was consisted of solid portion and contour was round and well-defined. The lesions showed marked heterogeneous enhancement (Fig. 1A) on contrast-enhanced CT.

The second patient was a 53-year-old man with a $1.5 \mathrm{~cm}$ sized mass in his left parotid gland tail (Case 2). The mass had been present for 5 months with rapid growth during the first 10 days. On physical examination, the lesion was rubbery hard, fixed, and painless. The patient had no history of trauma or other systemic complaints such as fever. On CT scans, the lesion contained cystic portion with round and well-defined contour. It showed peripheral rim enhancement on contrastenhanced CT scans (Fig. 1B)

The last patient was a 31-year-old man with a $1 \mathrm{~cm}$ sized mass in his right parotid gland tail (Case 3). The mass had been present for 9 months, and had been gradually increasing in size and was firm and fixed on palpation. The mass was painless and the patient had no history of trauma or systemic complaints such as fever. The lesion was oval shape and partially well-defined contour with solid component, and mild heterogeneous enhanced with contrast (Fig. 1C). All patients only complained about rapidly growing mass without any facial nerve palsy or pain. In all three patients, FNAC was performed for an initial diagnosis. The aspirates showed varying cellularity and each cell was oval to elongated spindle in shape (Fig. 2). Fascicles in an irregularly placed pattern were present, but some areas of the specimens showed no distinct pattern. A variable amount of stromal matrix may be present, which can cause misinterpretation such as a pleomorphic adenoma being diagnosed.

Therefore, all patients underwent parotidectomy under sus- 

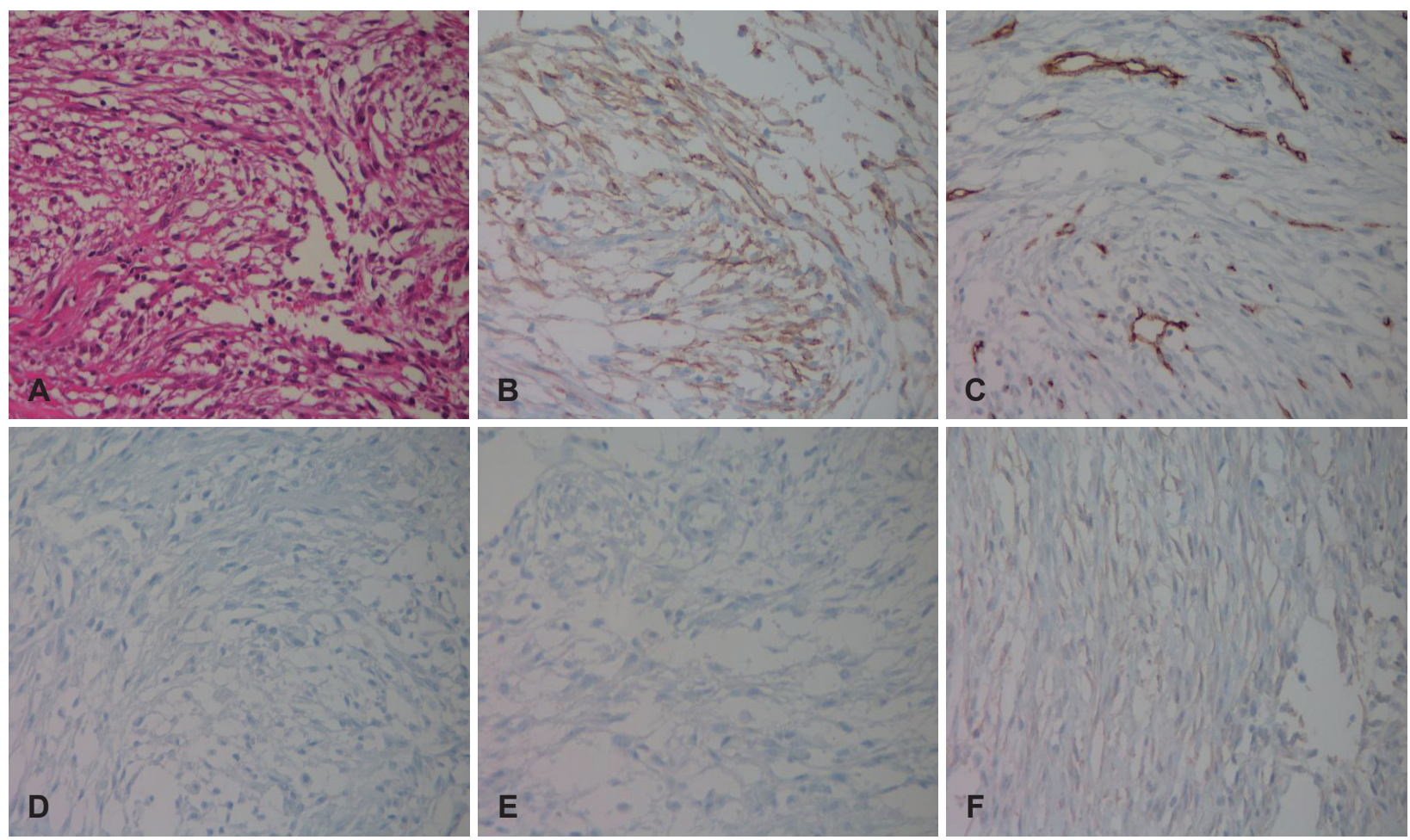

Fig. 3. Histologic findings of nodular fasciitis (NF) in the parotid gland. Higher magnification shows fascicles of plump but uniform spindle cells stained with hematoxylin and eosin (original magnification, $\times 400)(A)$. CD10 was expressed by all cases of nodular fasciitis of the parotid gland (B), and CD34 (C) also showed strong and diffuse staining. However, desmin (D), S-100 (E), and smooth muscle actin (F) stains showed negative reactivity in all three cases of NF of the parotid gland (original magnification, $\times 400$ ).

picion of a parotid gland neoplasm such as pleomorphic adenoma, and it was also thought to have condition with malignant potential due to its clinical features such as size growing and fixation to adjacent fascia. During operation, in one patient, the mass was found to be severely adherent to the platysma muscle and the buccal branch of the facial nerve, and as a result, the buccal branch of the facial nerve had to be sacrificed incidentally. However, the patient did not show any significant facial nerve palsy postoperatively.

In pathology reports, all of the lesions were non-encapsulated, but they were well-defined and discrete round or ovoid masses. Microscopically, these tumors showed variable cellularity on hematoxylin and eosin staining. Dense cellularity with varying amounts of collagenous stroma was present. A vaguely fascicular pattern, tissue cleavage, and microcystic change were present on examination at a lower power. Extravasated erythrocytes and scattered inflammatory cells were frequently found. Each cell was a myofibroblast which showed intermediate features between a fibroblast and a smooth muscle cell. On immunohistochemical (IHC) staining, positive reactivity to CD10, CD34, and SMA was shown. All the cases were negative for desmin, and S-100 protein. The tumors had infiltrated the adjacent muscle and salivary gland, and may have arisen in the fascia between the muscle and the salivary gland (Fig. 3).

\section{Discussion}

Salivary gland neoplasms represent less than $3 \%$ of all tumors in the general population and the differential diagnosis for common salivary gland tumors includes pleomorphic adenoma, Warthin tumor, and other low-grade malignant tumors. CT and FNAC has been widely used for the initial evaluation of parotid gland tumors, but they are of limited use in the differential diagnosis of a parotid gland tumor due to their relatively low sensitivity in distinguishing malignant from benign disease. Therefore, making an accurate diagnosis of a parotid gland tumor before surgery has been a challenge for many head and neck surgeons.

$\mathrm{NF}$ is an unusual benign reactive process of the soft tissues related to the fascia and is characterized by fibroblastic proliferation. In Korea, there have been several cases of NF, but most of them occurred in the external ear. ${ }^{7,8)}$ There has been only one case report of NF occurring in the parotid gland in Korea. Their case was similar to our cases in the aspect of young age, rapidly growing tumor and adherent to adjacent structures. 
However, our study presented three cases of NF in the parotid gland, so it can show viable characteristics of clinicopathology and imaging studies, thereby being helpful to understand the typical nature of NF in the parotid gland. Although several mechanisms had been proposed, including reactive and inflammatory processes, the pathogenesis of NF is still unknown. ${ }^{1)}$ Antecedent trauma has been suggested as an inciting factor. Only a minority of cases, however, have been reported to be associated with trauma, ${ }^{2,5,10)}$ and some authors have even insisted on the possibility of association between NF and the excessive use of mobile phones. ${ }^{11)}$ In this study, no case was associated with antecedent trauma. The most common clinical presentation of NF is a solitary rapidly growing mass with frequently associated pain and tenderness. Less frequently, compression of a peripheral nerve can cause numbness, paresthesia, and shooting pain. ${ }^{2)}$ On CT imaging, NF is generally seen as a relatively well-defined soft-tissue mass in a superficial location. ${ }^{10,12)}$ All of our cases were also located in the superficial lobe of the parotid gland with well-defined contour, and presented moderate enhancement with contrast. These features of NF in the parotid gland were nonspecific to make differential diagnosis in our cases. Interestingly, all of them showed adjacent fascial thickening CT scanning in our study, and even one case showed involvement of the masseter muscle.

Due to the clinical features of NF, such as rapidly growth of the lesion, and presence of a firm mass, malignant disease such as fibrosarcoma and malignant NF can be considered in the differential diagnoses of NF. NF may be easily mistaken for malignant neoplasm in both cytologic and histologic specimens, leading to unnecessary surgical treatment. Werning noted that 9 out of 30 cases of NF that he had consulted in had been misdiagnosed as a sarcoma. ${ }^{13)}$ Given the cytological similarity between both tumors, and the rarity of NF at this site, NF arising in the parotid gland can be easily misinterpreted as a pleomorphic adenoma or myoepithelioma. ${ }^{14)}$ Both pleomorphic adenoma, which shows spindle and plasmacytoid cells (hyaline cells), and NF may have a similar cytological appearance. ${ }^{15)}$ Therefore, some authors have suggested features such as the presence of spindle cells or a chondroid matrix, absence of admixed inflammatory cells, and the presence of mitotic figures as distinguishing criteria in the differential diagnosis. ${ }^{14)}$ IHC stains can provide further diagnostic support. Reactivity for SMA or S-100 can be used in the appropriate setting to confirm a diagnosis of NF or schwannoma.

In conclusion, although infrequently reported, NF in the parotid gland can mimic a parotid malignancy, even after assessment of the intraoperative findings. Moreover, another potential diagnostic pitfall is NF being mistaken for a pleomorphic adenoma on FNAC and CT scanning. Most cases of NF of the parotid gland show occasional adjacent fascial thickening and moderate enhancement on contrast-enhanced CT. Therefore, NF should be considered in the differential diagnosis of benign and malignant parotid tumors.

\section{Acknowledgments}

This work was supported by Biomedical Research Institute grant, Kyungpook National University Hospital (2014).

\section{REFERENCES}

1) Koenigsberg RA, Faro S, Chen $X$, Marlowe F. Nodular fasciitis as a vascular neck mass. AJNR Am J Neuroradiol 1996;17(3):567-9.

2) Leung LY, Shu SJ, Chan AC, Chan MK, Chan CH. Nodular fasciitis: MRI appearance and literature review. Skeletal Radiol 2002;31(1):9-13.

3) Matusik J, Wiberg A, Sloboda J, Andersson O. Fine needle aspiration in nodular fasciitis of the face. Cytopathology 2002;13(2):128-32.

4) Chen KT, Bauer V. Nodular fasciitis presenting as parotid tumor. Am J Otolaryngol 1987;8(3):179-81.

5) Dahl I, Jarlstedt J. Nodular fasciitis in the head and neck. A clinicopathological study of 18 cases. Acta Otolaryngol 1980;90(1-2): 152-9.

6) Atula T, Greénman R, Laippala P, Klemi PJ. Fine-needle aspiration biopsy in the diagnosis of parotid gland lesions: evaluation of 438 biopsies. Diagn Cytopathol 1996;15(3):185-90.

7) Yoon TM, Kim RY, Cho SY, Lee JS. Two cases of nodular fasciitis in external ear region. Korean J Otorhinolaryngol-Head Neck Surg 2011;54(10):711-4.

8) Koo MB, Lee WK, Lee JH, Yeo CK. Nodular fasciitis presenting as a retroauricular mass. Korean J Otorhinolaryngol-Head Neck Surg 2008;51(3):296-9.

9) Kim KH, Cho KH, Hong YH, Kim HK, Song KY. A case of nodular fasciitis of the parotid gland. Korean J Otorhinolaryngol-Head Neck Surg 2001;44(9):1006-9.

10) Shin JH, Lee HK, Cho KJ, Han MH, Na DG, Choi CG, et al. Nodular fasciitis of the head and neck: radiographic findings. Clin Imaging 2003;27(1):31-7.

11) Pereira $C$, Edwards M. Parotid nodular fasciitis in a mobile phone user. J Laryngol Otol 2000;114(11):886-7.

12) Toledo AS, Rodriguez J, Cuasay NS, Koch DB, Ray CG 3rd, Langer BG, et al. Nodular fasciitis of the facial region: CT characteristics. J Comput Assist Tomogr 1988;12(5):898-9.

13) Werning JT. Nodular fasciitis of the orofacial region. Oral Surg Oral Med Oral Pathol 1979;48(5):441-6.

14) Saad RS, Takei H, Lipscomb J, Ruiz B. Nodular fasciitis of parotid region: a pitfall in the diagnosis of pleomorphic adenomas on fineneedle aspiration cytology. Diagn Cytopathol 2005;33(3):191-4.

15) Sciubba JJ, Brannon RB. Myoepithelioma of salivary glands: report of 23 cases. Cancer 1982;49(3):562-72. 